\title{
Tuberculosis of the cervix: a rare cause of postcoital bleeding and inadequate cervical smear
}

\author{
M. Moustafa $\cdot$ A. Montgomery
}

Received: 9 May 2010 / Accepted: 3 June 2010 /Published online: 16 June 2010

(C) Springer-Verlag 2010

Keywords Tuberculosis · Granulomatous lesion ·

Cervical smear $\cdot$ Colposcopy $\cdot$ Loop diathermy (LLETZ)

\section{Introduction}

Tuberculosis of the cervix is a rare finding in the economically developed world. This is a case which presented as postcoital bleeding and inadequate cervical smears. Granulomatous cervicitis was revealed, with mycobacterium isolated as the causative organism. The incidence of tuberculosis is on the rise in the UK [1], attributable to increased numbers of immigration, foreign travel and the HIV pandemic. With this in mind, there should be a high index of suspicion of tuberculosis in women with an abnormal cervical appearance, especially from areas where HIV and TB are endemic.

Tuberculosis of the cervix in the economically developed world is rare. It is reported as accounting for $0.1-$ $0.65 \%$ of tuberculosis [2], and being the minority of cases of genital tract tuberculosis 5\% [3]. This becomes more common in the less economically developed world, $19 \%$ in India [4], versus $0.07 \%$ in the USA [5]. Therefore, this differential should be at the forefront of our minds in those presenting with vaginal bleeding, especially if the patient

Declaration of interest The authors report no conflicts of interest. The authors alone are responsible for the content and writing of the paper.

M. Moustafa $(\square) \cdot$ A. Montgomery

Frimley Park Hospital,

Surrey, UK

e-mail: magdy_moustafa@live.co.uk has origins where tuberculosis is endemic. However, living in an era where tuberculosis and drug resistance are on the rise $(5.5 \%$ increase in cases in the UK between 2008 and 2009 [1]) and with international travel and immigration being the greatest they have ever been, this is a significant differential, and one that must not be overlooked.

\section{Case presentation}

A 34-year-old lady of Nepalese origin was referred to the colposcopy clinic with a 6-month history of postcoital bleeding, dysmenorrhoea and an inadequate smear on two occasions. She had no intermenstrual bleeding, dyspareunia, weight loss, abdominal pain or bloating.

She had had no symptoms of cough, unexplained fever or night sweats. The patient had been a UK resident for 9 years. On moving to the UK, a chest clinic referral was made due to immigration from a high-risk area. Chest Xray was clear, and the patient had a visible BCG scar on her upper arm. There was no known contact with anyone with tuberculosis in the preceding 9 years.

There were no systemic signs or stigmata of tuberculosis or carcinoma. Vaginal examination was unremarkable. A cervical smear was taken again before colposcopy. The colposcopic impression was of a large cervical ectopy. The cervix was friable, and the ectopy was removed using large loop excision of the transformation zone (LLETZ). The cone biopsy was sent for histopathological analysis. The cervical smear showed no dyskaryotic cells. The results of the LLETZ cone biopsy revealed an active granulomatous cervicitis.

Systemic investigations were carried out to look for a primary source of TB. None were evident. Chest X-ray, 
Ishihara test and visual acuity were all normal. HIV testing was negative. The patient's husband and immediate family were counselled and screened for tuberculosis. These tests were negative.

Anti-tuberculosis quadruple therapy was commenced for a period of 2 months, which was complicated by a pruritic rash. However, liver function tests remained normal throughout. Rifampicin and isoniazid continued for the full 6 months. The patient has responded well to treatment, and a follow-up smear has been normal.

\section{Discussion}

Genital tract tuberculosis was first identified and described by the famous Italian anatomist Giovanni Battista Morgagni in 1744 following a post mortem of a patient who was found to have caseating material within her uterus and fallopian tubes. Since this first description in the eighteenth century, genital tract tuberculosis has continued to be of interest in gynaecology not only for its rarity in the developed world to the more common place in countries like India where tuberculosis is endemic but also to its pathogenesis in subfertility [6].

The incidence of genital tract tuberculosis has been difficult to gage. This is due to an unknown number being asymptomatic and the discovery of some cases being incidental [7]. These problems along with the varying incidence of primary tuberculosis across different socioeconomic classes and geographical areas see the incidence varying greatly from $0.07 \%$ to $19 \%[4,5]$. Tuberculosis of

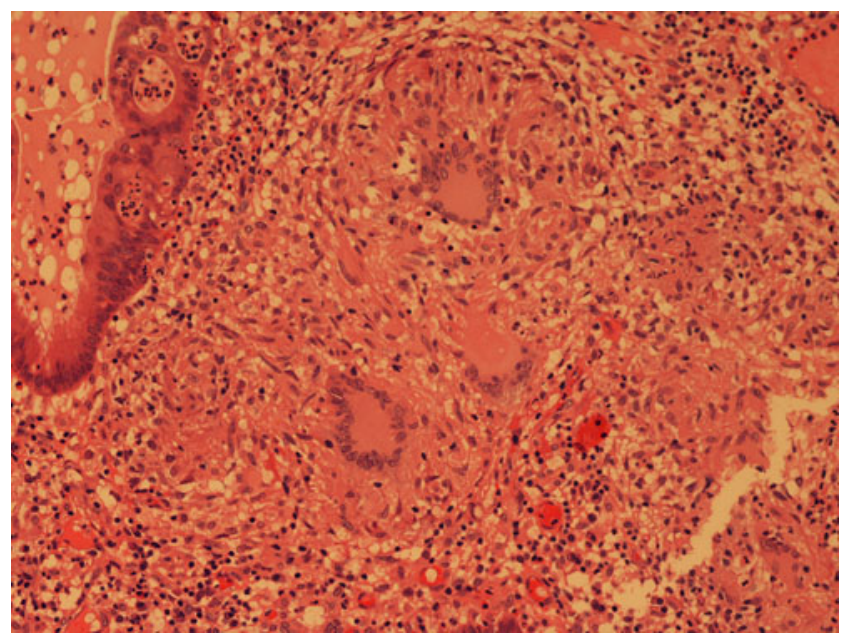

Fig. 1 High-power view. There is epitheloid cell granuloma rich in Langhan's type giant cells. Caseation necrosis is not seen in this field

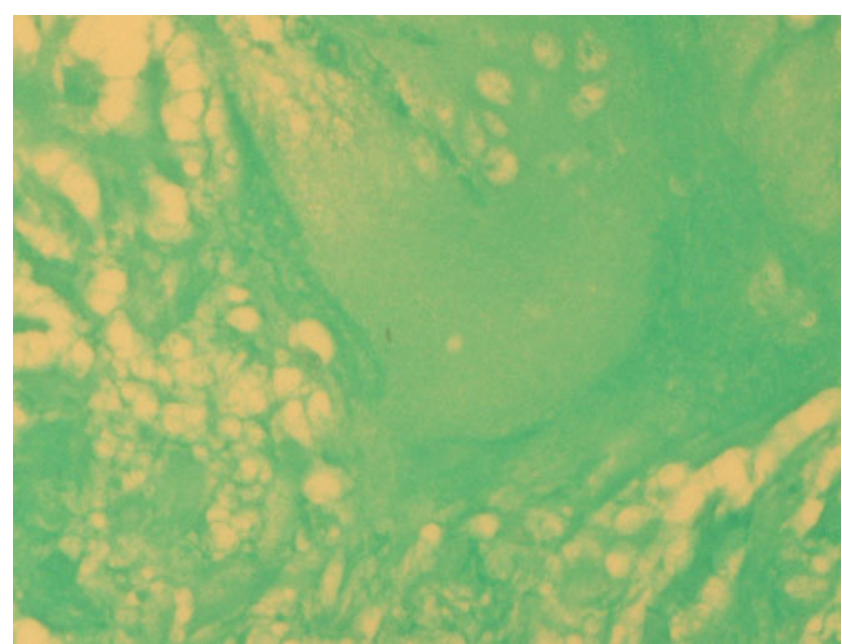

Fig. 2 Ziel-Neelson stain demonstrated occasional acid and alcohol fast bacilli

the cervix is a lesser common site of the genital tract to be affected, ranging from $5 \%$ to $15 \%$ [8] (Fig. 2).

The primary focus in tuberculosis is most commonly the chest, with transmission from droplet spread from those infected. Pelvic organs are infected by haematogenous, lymphatic spread or direct extension [9]. It has been suggested that primary genital tract tuberculosis can be contracted by a partner with tuberculous epididymitis or infected sputum used as a sexual lubricant [10]. This case demonstrates that no primary source elsewhere has been identified, and the patient's partner has tested negative.

The gold standard for diagnosis is microbiological isolation. This was not necessary in our case as mycobacterium had been visualised histologically (Figs. 1, 2).

The standard treatment is 6 months of anti-tuberculosis therapy. Testing the partner and close relatives is essential as per public health guidelines.

\section{Conclusion}

In conclusion, tuberculosis of the genital tract in the developed world is rare, but with the increase in tuberculosis, this is going to become more prevalent. It needs to be considered as a potential diagnosis presenting with vaginal bleeding or other cervical symptoms, especially if the particular patient has origins from a country where TB is endemic. Living in an era where tuberculosis and its drug resistance is on the increase, and with international travel and immigration being the greatest they have ever been, this is a significant differential that must not be overlooked. 
Acknowledgements We would like to thank Dr. Christopher Smith, Consultant Histopathologist, Frimley Park Hospital, and Colonel Hoad, Respiratory Physician, Frimley Park Hospital.

\section{References}

1. Health Protection Agency (2010) http://www.hpa.org.uk/web/HPA web\&HPAwebStandard/HPAweb_C/1267551043033. Accessed 6 May 2010

2. Lamba H, Byrne M, Goldin R, Jenkins C (2002) Tuberculosis of the cervix: case presentation and a review of the literature. Transm Inf 78:63-66

3. Rock JA, Jones HW (eds) (2003) Te Linde's operative gynaecology, 9th edn. Lippincott Williams \&Wilkins, Philadelphia, pp 697-698
4. Bateman BG, Nunley WC, Kitchin JD et al (1986) Genital tuberculosis in reproductive age women. J Reprod Med $31: 287$

5. Klein TA, Richmond JA, Mishell DR (1976) Pelvic tuberculosis. Obstet Gynecol 48:99

6. Tripathy SN et al (1998) Gynaecological tuberculosis: an update. Ind J Tub 45:193

7. Goldin AG, Baker WT (1985) Tuberculosis of the female genital tract. J Ky Med Assoc 83:75

8. Schaefer G (1976) Female genital tuberculosis. Clin Obstet Gynecol 19:23

9. Sinha R, Gupta D, Tuli N (1997) Genital tract tuberculosis with myometrial involvement. Int J Gynaecol Obstet 17:305-308

10. Chowdhury NNR (1996) Overview of tuberculosis of the female genital tract. J Indian Med Assoc 94:346-361 